\title{
Application of dynamic capabilities of the economic system for the purposes of sustainable innovation development
}

\author{
Sergey Knyazev \\ Department of Economics and Management \\ Volgograd State Medical University \\ Volgograd, Russia \\ E-mail: sergey-cknyazev@mail.ru
}

\begin{abstract}
The author investigates the logical relationships between core competences and dynamic capabilities within the resource approach. In the article the concept of an estimation of dynamic capabilities and their evolution is formulated.
\end{abstract}

Keywords - core competence, resource-basedview, dynamic capabilities, innovation

\section{INTRODUCTION}

Tendencies of acceleration, complication and chaotization of changes in the socio-economic processes of economic systems at various levels put before the governing bodies an important task - the creation of a stable state of well-being and balance. This non-trivial task consists in the search, approbation and adaptation of such managerial decisions that will provide the economic system with the benefits in the short and long term. It should be said about such a configuration of economic processes that will be able to produce effective activity under constantly changing conditions. The importance of this task is due to the high risk of the collapse of the economic system in the absence of such a configuration, as well as great benefits if it exists.

\section{MATERIALS AND MethodS (MODEL)}

In this paper, several models with high heuristic potential are used. Based on the resource theory of the firm, the main provisions of which are extrapolated to large-scale systems, the concept of core competencies that form the basis for achieving competitive advantages is considered. At the same time, resources are classified within the theory of factors of production, developed by Oleg Inshakov. The concept of core competences offered by Gary Hamel and Coimbatore Prahalad gave the development of the concept of dynamic capabilities, the basic provisions of which were formulated by David J. Tees. To construct a hypothesis about the ways of evolution of dynamic capabilities, the concept of spiral dynamics developed by Clare Graves, Don Beck and Chris Cowan was taken as a basis.

\section{RESULTS AND DISCUSSION}

At economic systems of various level it is possible to find the universal element peculiar to all levels. This element is the resources that are controlled by economic systems at the nanolevel, microlevel, mesolevel, and macrolevel. It can be assumed that these resources are divided into two major types. The first of these is transformational resources. They are transformed as they become involved in activities. This type includes human, material and technical and technological resources. The second type of resources is transactional resources, which include institutional, information and organizational resources [1].

The economic entity, involving these resources in the reproduction processes as a means of achieving their goals, participates in the process of learning the ways of the best use of resources. The economic entity acquires competencies that can be divided into core and secondary competencies in the process of learning.

Competence must have three characteristics in order to be a core competence [2]. First, it should extend to the entire economic mechanism of the system. Secondly, it must directly provide a sustainable competitive advantage (that is, in comparison with other comparable systems, provide the best possible use of resources to this economic system). Thirdly, the core competence is difficult to copy by competitors. two research questions help to identify the core competence- "what does the economic system do best?" and if the first question doesn't give a clear answer, "why does the system do it best?". To conceptualize core competences, it may take several iterations. Examples of core competences at different levels can be:

- at the nanolevel - the ability to do home repairs with their own hands,

- at the microlevel - ability to deliver cargo on time and safely,

- at the mesolevel - the ability to attract investment for the development of clusters in the region, 
- at the macrolevel - the ability to transport natural resources.

As a rule, core competence deals with several types of resources. However, in a simplified form, it is possible to make correspondences between the type of resource and an example of core competence:

- human resources - a unique system of placement of personnel,

- material resources - the use of exceptional components,

- technical and technological resources - use of original technology,

- information resources - use of an exclusive knowledge management system,

- organizational resources - application of special systems and procedures,

- institutional resources - the formation of unique rules and regulations.

The configuration of core competencies forms a business model of the economic system. The business model answers the main question: what value does the economic system create? The business model is also responsible for deciding who is the receiver of the value, how it is produced, by what channels it is transmitted, and so on. An expanded view of the business model gives the canvas of the business model of Alexander Osterwalder and Yves Pigneur [3]. Business models are created to achieve the planned results.

Secondary competencies of the economic system for the analysis of practical activities can be conveniently divided into synergistic and non-core.

Synergistic secondary competencies work together with core competencies, enabling them to more efficiently convert resources into created value.

Non-core secondary competences arise due to historical or opportunistic reasons (for example, in the process of diversification of activities). They exist relatively autonomously from core competencies. If the economic entity is able to integrate non-core competencies into the existing business model, then they become synergistic. It is also possible to rotate the business model (for example, in a crisis). Then non-core competences can form the basis for the formation of an updated business model. In other conditions, there is a tendency to get rid of non-core competencies.

In any case, the economic entity faces a choice - to continue to apply its own secondary competencies or engage third-party economic entities that have this competence as the core one. The solution depends on the ratio of decreasing control costs to increasing transaction costs.

Examples of such choices are:

- at the nanolevel: to make repairs in the house yourself or to hire a specialized repair team,

- at the microlevel: to deliver goods independently or to conclude an agreement with a logistics company,
- at the mesolevel: to attract investors to regional clusters independently or to expect to allocate funds under targeted programs,

- at the macrolevel: to concentrate on the delivery of natural resources for export or on processing.

The main task of regular management of the economic system within the framework of the resource concept is to turn the application of core competencies into a routine. Routineization of core competencies institutionalizes the business model, fixing its competitive advantages within the economic system, allowing to obtain significant economic results in comparison with other systems.

However, in the long term, a change in the external environment and (or) internal goals of the system can make the strengthened business model uncompetitive. In order to prevent such a scenario, the economic system needs to develop its dynamic capabilities.

Dynamic capabilities represent the ability to reconfigure core competencies (that is, in essence, by changing the business model) [4]. It can be said that this is a routine for changing routin (metaroutin) [5]. If the core competencies form the statics (business model) of the economic system, then the dynamic capabilities characterize the system in dynamics. Dynamic capabilities characterize the behavior of the economic system in the continuum from isolation (in order to avoid copying core competencies) to openness (in order to study the best experience of other systems).

Often the process of acquiring dynamic capabilities is interpreted within the framework of the evolutionary approach. It consists of the processes of searching, evaluating and routineization new core competencies.

The search for core competencies is carried out within the boundaries of the economic system. Often "secondary" synergetic competencies become the "supplier" of new core competences, which can substantially transform the entire business model.

The evaluation of core competences is carried out in three modes:

- ex-ante assessment concentrates on predictive behavior of the economic system with a new configuration of core competences,

- on-going assessment monitors the actual behavior of the business model in the present tense,

- the ex-post evaluation summarizes the retrospective analysis of core competences and their configuration.

Routinization is carried out within the framework of selflearning processes, experiment, repetition and the identification of the best competencies.

If you expand the perspective of the look at the dynamic capabilities, you can see that the reconfiguration of the business model is more complex: 
- preservation core competencies: dynamic capabilities involve deciding which core competencies will remain unchanged in the new configuration,

- modernization: in the framework of reconfiguration, some core competencies can be improved,

- innovation: new core competencies are added to the existing configuration,

- elimination: Some of the core competencies during reconfiguration can be removed from the business model (analogous to the microlevel is the phenomenon of organizational forgetting).

This four-part feedback model allows organizing learning loops in the economic system, which increases the chances of implementing a strategy of sustainable innovation development.

However, the functioning of dynamic capabilities can be understood not only in the context of evolutionism as a selective process. There are at least three more ways to strategically update. If the selective mechanism is a passive form of adaptation to the external environment, then the administrative mechanism for the formation and functioning of dynamic capabilities refers to the active form. Here the emphasis is placed on the objectives of the economic entity. It is the figure of the "Owner" (the head of the family, the company, the region, the state) that becomes dominant and endowed with such qualities as "vision" (exact prediction of the future), "knowledge" (complete and rational ideas about phenomena), "will" (acceptance of necessary decisions at the right time). However, this approach does not take into account the decentralization of power that has actually developed in many economic systems. Perception of the functioning of dynamic capabilities as a network mechanism largely removes this problem. Relatively autonomous subsystems of the economic system due to the diffusion of innovations (mainly process ones) ensure the development and routineization of core competencies. The cognitive approach focuses on changing the beliefs of decision-makers. Replacement of established patterns of thinking and stereotypes that do not work in new conditions leads to new forms of behavior in which the reconfigured business model is mastered.

In general, for the management of dynamic capabilities horizontal connections are typical, and not vertical ones. Particular attention should be paid to the achievement of consensus on vision, goals, values and competences.

A model for assessing dynamic competencies has not yet been created. However, it seems that the following parameters should be taken into account in this model:

- degree of proactivity. This is the time gap between the action of the system and the external event, "in response" to which the action is committed. The more distant the external event in the future in relation to the action of the system, the more proactive is the economic system and the more developed its dynamic capabilities. The system is called reactive (negative proactivity), if an external event precedes the reaction time to this event. One of the quantitative indicators of this characteristic will be the speed of reconfiguration of the business model.

- influence on the created value. Dynamic capabilities can adversely affect the magnitude and quality of the value created. For example, this can happen when the focus of attention is shifted from terminal to instrumental goals, from goals to tasks and instruments. Positive influence on the produced value is rendered by such dynamic capabilities, which are based on the triple loop of learning and take into account changes in the preferences of consumers of the generated value.

When these two parameters are applied to the coordinate plane, we can distinguish four variants of the strategic behavior of the economic system on the basis of dynamic capabilities.

The variant "Collapse" arises, when the economic entity made the wrong decision in response to an external event that had already happened. This solution reduces the value created and indicates the reactivity of the system. The "Necessary measure" option is observed in case of an increase in the generated value in response to an external event that has occurred. Negative impact on the produced value in case of premature actions form the "Wrong forecast" variant: although the system is proactive, but the steps taken in advance led to the opposite of the planned one. Finally, if dynamic capabilities are highly developed, and the organization has a proactively and positively impact on value, then the "Wise Solution" option arises.

From a scientific and practical point of view, not only the models for assessing dynamic capabilities are interesting, but also it is interesting how dynamic capabilities develop over time. In our opinion, for these purposes it is convenient to use the already existing models of the evolution of complex systems. An example of such a model is "spiral dynamics" [6]. The totality of external conditions, values, goals and means forms so-called memes. Memes evolve on an ascending spiral. Let's try to apply the concept of spiral dynamics to dynamic capabilities, especially as it acquires increasing popularity among managers.

The first level can be described as "Survival". Dynamic capabilities have just begun to form in the system. The conservative reaction to external events prevails, when the main task is to preserve, not to multiply and develop. The subsystems are disunited, the principle "each person is responsible for himself, not for others" prevails.

At the second level - "Rituals" - strong leaders dominate, which create the appearance of understanding the processes that are taking place. And although understanding in this case is not more than in the J. March's Garbage Can Model, but there is a ritualization of the decision-making process. The power of leaders is not based on strong personal charisma, but on the representations of followers about the sacred connection of leaders with reliable sources. There is a trust based on some successful solutions that increase the value created and are popularized in the system. Attempts to influence external events are not observed, but a spontaneous and subjective forecasting system is being formed. 
The third level - "Power" - shifts the focus from ritualized decision-making processes to charismatic leaders who have confidence in their intuitive decisions. On the basis of their conviction, such leaders are able to realize their decisions through transactions, coercion, deception. A leader is a carrier of dynamic capabilities.

The fourth level - "Order" - is characterized by the institutionalization of dynamic capabilities: the establishment of norms and rules, the distribution of responsibilities, some degree of decentralization. Reconfiguration of core competencies occurs within the framework of formalized processes in accordance with established rules and procedures.

"Risk" is the name of the fifth level. In this case, we mean conscious risk-taking of innovative solutions [7]. Dynamic capabilities play the role of "benefit seeker". The system is prone to frequent reconfigurations by the decision of personified management bodies. Values of competition, customer orientation, entrepreneurship are strongly expressed at this level.

"Cooperation" dialectically contradicts the previous level in the value of competition. At the sixth level, dynamic capabilities are directed towards processes of internal and external integration on the principles of voluntariness and friendliness. Sharing benefits from the created value is the basic principle of cooperation between economic systems.

The next level - "Chaos" - assumes the predominance of fuzzy logic over rigid structures. Integral system thinking of personalized leaders controls the dynamic capabilities of the system, producing innovations that increase the value created.

Finally, the eighth level is most popular due to the socalled "turquoise organizations". These are systems whose dynamic capabilities function at the eighth level of Integrity, providing inter-system integration by creating multiple network-type relationships. Diffusion of innovation and reconfiguration of core competencies are "natural". The change in the business model creates a basis for sustainable innovative development in a turbulent environment [8].

\section{CONCLUSION}

The main attention is paid to logical interrelations in the chain "goal - resources - core competences - dynamic capabilities". The proposed concept of assessing the level of dynamic capabilities of an economic system based on two characteristics ("degree of proactivity" and "influence on the value created") allowed us to formulate four variants of the behavior of economic systems in a turbulent environment, but it needs further refinement and verification. For example, a clear parametrization of the two applied characteristics is necessary. This will create a model and methodology for assessing dynamic capabilities. In particular, such a technique could help to understand not only the level of development of dynamic capabilities, but also the formation of a management model that would contain algorithms for transition from one stage to another. Therefore, with the help of the evaluation technique, it will be possible to test the hypothesis about the evolution of dynamic capabilities formulated in the paper.

\section{References}

[1] Inshakov O.V. Economic genetics as the basis of the evolutionary economy [Ekonomicheskaya genetika kak osnova evolyutsionnoy ekonomiki] // Bulletin of the VolSU. Ser. 3, The Economy. Ecology [Vestnik VolGU. Ser. 3, Ekonomika. Ekologiya]. - Issue 10. Volgograd: Publishing house of VolSU, 2006. - P. 6-16.

[2] Prahalad, C. K., Hamel, G. 1990. The Core Competence of the Corporation, Harvard Business Review, Vol. 68, No.3, pp.79-91.

[3] Osterwalder A. Building Business Models: A Handbook of the Strategist and Innovator [Postroyeniye biznes-modeley: Nastolnaya kniga stratega i novatora] / Alexander Osterwalder, Yves Pigneur; Trans. with English. - Moscow: Alpina Pablisher, 2011. - 288 p.

[4] Teece D. J. Explicating dynamic capabilities: the nature and microfoundations of sustainable enterprise performance // Strategic Management Journal. 2007. \# 28. P. 1319-1350.

[5] Eisenhardt K. M., Martin J. K. Dynamic capabilities: What are they? // Strategic Management Journal. 2000. \# 21. P. 1105-1121.

[6] Beck D., Cowan C. Spiral Dynamics. Managing values, leadership and change in the 21st century [Spiralnaya dinamika. Upravlyaya tsennostyami, liderstvom i izmeneniyami v XXI veke]. - Moscow: BestBusinessBooks, 2010. - 424 p.

[7] Mitrofanova I., Russkova E., Buyanova M. Specific risks of implementation of infrastructure megaprojects in regions of modern Russia // Russia and the European Union. Development and Perspectives / E.G. Popkova (ed.). Springer International Publishing AG, 2017. (Ser. Contributions to Economics). P. 75-80.

[8] Inshakova E., Inshakov O. Problems and mechanisms of special economic zones development in Russian nanoindustry // The Strategies of Modern Science Development: Proceedings of the IX International scientific-practical conference. North Charleston, SC, USA, 16-17 October 2015. - North Charleston: CreateSpace, 2015. 